\title{
THE POWER CURVE: TEACHING THE ESSENTIALS OF FLIGHT
}

\author{
Juan R. Merkt \\ Concord Field Station, Harvard University \\ Bedford, Mass. 01730
}

\begin{abstract}
If you were to skim through a text on classical aerodynamics for engineers, and then take a close look at one presenting basic theory of flight for pilots, you may be struck by the similarities rather than by the differences between the two. Of course, the former will contain more detailed information and give it in a much more technical and complicated way. Yet, both will be organized similarly, starting with isolated, basic components and building up to some major applications of the theory. This is the traditional way of teaching basic theory of flight to pilots. This paper proposes an alternate approach. Rather than beginning with the underlying causes of flight, it proposes to unravel basic principles by starting with the consequences of aerodynamic phenomena. Perhaps the best way of illustrating how this opposite approach may work is by presenting a simple model. Here, I show how the power curve, representing the most generalized consequence of all aerodynamic processes, could be used as a vehicle to introduce basic principles of flight to beginner pilots. This approach may allow schools to standarize teaching of basic aerodynamics and may permit students to increase their understanding of flight in a way they can effectively apply this knowledge during initial training. Although a solid understanding of how airplanes fly is not the only goal of a sound training program, gaining a high level of understanding in this vital area should be one of the most crucial requirements for ensuring competency and safety among professional pilots.
\end{abstract}




\section{Introduction}

Show me a pilot who can explain a power curve and I will show you someone who understands the very essence of flight. There is no other concept in the theory and practice of flight as fundamental and far reaching as that embodied by a power-speed relationship. It is at the heart of aerodynamic theory, aircraft design, flight-control, aircraft perfomance, and fuel economy. Commonly, a power curve defines how the power required for straight-and-level flight changes with airspeed, though such a relationship can be easily extended to any other steady-state phase of flight (e.g. unaccelerated climbs, descents, and turns). Most likely, all pilots have glanced at this peculiar U-shaped curve during ground-school days, or have at least been cautioned by a flight instructor during operations within the "region of reversed command" or "backside of the curve". Yet, probably only a few pilots understand why the power required for flight varies with airspeed or how they could use a power curve to optimize aircraft performance during flight (Miller, 1987). This lack of understanding may be due to the way basic principles of flight are traditionally presented in texts and taught in primary training courses, as well as the academic background of most civilian student pilots.

The basic principles behind power-speed relationships are of course fully explained in aeronautical engineering texts (McCormick, 1979; Milne-Thomson, 1958; Mises, 1945; Prandtl and Tietjens, 1934; Warner, 1936). Yet, for the average non-engineering aviation student, extracting the important concepts behind a power curve from such technical information can be a difficult task. Key elements of the theory and their practical meaning are simply lost among obscure technical and mathematical descriptions. On the other hand, some widely used nontechnical literature, which could specifically help beginner pilots, provide incomplete explanations (FAA, 1980b; Jeppesen-Sanderson, 1988, 1989; Kershner, 1979) and, unfortunately, even misleading notions about the power-speed concept (FAA, 1980a,b; FAA,1987; Navarre 1987a,b). Only a few authors (Hurt,1965; Dole, 1989) present applied aerodynamic theory more thoroughly, and do it with as little mathematics as possible. Regardless of their level of complexiiy, however, all of these texts follow an approach that one could call the "engineers' approach".

What is an "engineer's approach"? In a classical sense (Warner, 1936), engineers begin by studying the isolated causes, as opposed to the consequences, of aerodynamic processes in order to understand principles they can apply to the design of aircraft. First, they focus on the physical properties of air; its behavior when flowing around objects and surfaces of different shapes; and the forces generated under varying airflows. Then, they design parts or whole structures that should generate the forces they want, under specific conditions. Finally, the prototype is tested (during flight or in wind tunnels) and, if necessary, later improved to meet with performance specifications. Thus, the "finished product" for an engineer is not just the physical aircraft but its performance, best encapsulated by power-curves, under different conditions of flight (Mises, 1945). The reason engineers start at the "bottom" (causes) rather than at the "top" (consequences) in their search for working principles is simply because they cannot start by measuring the performance of an aircraft that doesn't yet exist!

We can carry the engineer analogy further, not only to the way theory is presented in aviation textbooks, but also to the way principles of flight are taught in ground-training courses. Even when stripped of complicated mathematics, typically these courses follow the traditional approach by introducing and teaching basic principles as isolated phenomena. Only later, do a host of seemingly unrelated factors come together under the headings of "performance" or "cruisecontrol". This approach, however, may suffer from an inherent weakness if used for teaching 
the basics of flight to non-engineering students. Without the benefits of a solid background in physics and advanced mathematics, for example, a student may have a difficult time grasping the theoretical and practical implications of isolated, abstract concepts such as "lift" or "angle of attack", which he cannot "see" or "feel" during training flights. Later on, when the "big picture" (e.g. performance theory) is presented, several underlying elements of the theory are simply omitted, since understanding of these basic concepts is taken for granted. Often, the result is a student pilot who by this time may have acquired the necessary "skills" to fly an airplane, but who may lack satisfactory understanding of aircraft performance and its underlying principles. Removing this flaw from current primary flight-training programs does not necessarily mean that we have to start teaching advanced calculus and physics to beginner pilots (although some knowledge of these fields would certainly be beneficial). There is a more simple solution.

The goal of this paper is to suggest a alternate approach for introducing basic elements of flight theory to non-engineering aviation students by literally turning the engineer's approach upside-down. Rather than beginning with the underlying causes of flight, as an engineer would, it proposes to unravel basic principles by starting with the consequences of aerodynamic phenomena. And this is where power curves excel. A power curve (namely the relation between power and speed during flight) represents, after all, the most generalized consequence of all aerodynamic processes. Thus, the power-speed concept, once stripped from confusing technicalities and presented correctly, can itself become a powerful tool for grasping and clarifying essential principles of flight. No other concept provides such a rich framework for teaching aerodynamic theory and for putting into practice the basic principles taught in the classroom.

An analogous approach already exists in a different scientific field where power curves have been used for research with tremendous success. Physiologists, for example, routinely use power-speed relationships as an experimental tool to investigate basic principles underlying the mechanics and energetics of animal locomotion (Schmidt-Nielsen, 1972; Taylor et al., 1982; Tucker 1973). They begin their studies by obtaining power measurements of live animals running on treadmills, swimming in watermills, or flying in wind-tunnels at different steady speeds. The physiologists' approach for investigating basic principles of locomotion is thus diametrically opposite to that of engineers. After all, physiologists have to work with a "finished product", namely the whole, performing animal. They need to start at the "top" and work their way "down" to understand the underlying principles of animal locomotion. In an analogous manner, we can use power curves derived from aircraft performance to begin our study of the principles of mechanical flight.

We could view this "top-to-bottom" approach to studying flight as being operator (pilot), rather than designer (engineer), oriented in that the former begins with actual aircraft performance as a framework to investigate underlying principles (Figure 1). The designer oriented approach has proven ideal to teach aerodynamic theory to engineering students, but the opposite approach may be better suited for teaching the same principles to student pilots. Why? The answer lies in the actual process we need to go through in order to explain or "derive" a power curve.

We can think of the process of going from top to bottom in our search for basic principles as one that consists of going through different "levels" of explanation (Figure 1). Each level contains all the essential components that explain the immediate next level up. By starting at the top, we only need to be concerned with the level immediately below to begin our search for explanations. These explanations (or underlying principles), however, are only brought up in the context of the top level. This has some great advantages over the "bottom-to-top" approach in terms of teaching basic theory of flight to pilots. First, regardless of the level of complexity of a 


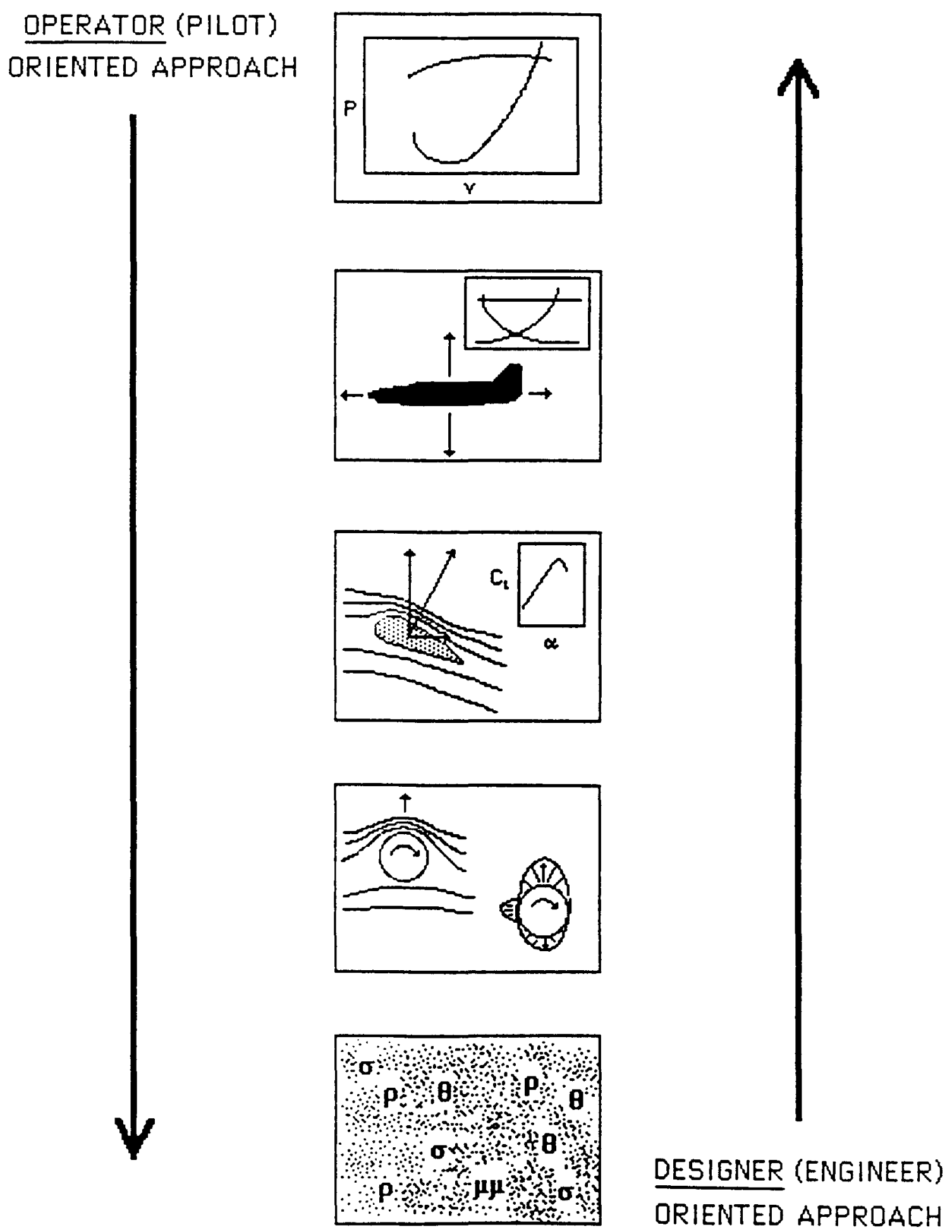

Figure 1. Schematic representation of two opposite approaches for teaching the theory of flight. The designer (engineer) oriented approach starts by studying the causes of all aerodynamic phenomena and proceeds up to higher-level consequences. The operator (pilot) oriented approach on the other hand, starts with the highest consequences of aerodynamic processes (e.g. performance) and proceeds downward to unravel underlying principles. The latter may be better suited for teaching basic theory to student pilots. 
course and previous preparation of the student, the new approach enables the student pilot not only to view all the relevant components when needed, but also to appreciate the important ways in which these different components interact with one another to result in a given state of aircraft performance (e.g. low speed, level flight). The benefits from understanding how basic elements of flight interact go far beyond mere knowledge of some isolated facts. The student can now begin to apply this understanding to real flight situations. Second, we can proceed downward in our search for underlying principles only after the preceeding level has been fully understood by the students. This would give flexibility in the design of a course while ensuring that at least some minimum educational standards are being met. If required by the course, we can continue further down into deeper levels. Perhaps the best way to show how this "top-to-bottom" approach may work is to illustrate it by a using a simple model.

\section{The Model}

Here I illustrate how one could take full advantage of power curves to teach beginner pilots the essentials of flight theory. For brevity, the following model focuses on a typical power curve for fixed-wing propeller aircraft in straight-and-level flight. The approach, however, can be extended to illustrate almost any other facet of flight in both propeller and jet aircraft. For example, one could combine "power required" and "power available" curves to study the dynamics of unaccelerated climbs, descents, and turns. The method is also ideal to investigate the effects of many factors (e.g. weight, altitude, aircraft-configuration, wind) on aircraft performance. Finally, force curves, rather than power curves, can be used to introduce the dynamics of non-steady phases of flight such as take-off and landing rolls (see Hurt, 1965; Kershner 1985).

In the first part of the model I describe how a typical power-speed relationship is derived for level flight. The reader will note that in deriving the power curve I have omitted explanations of certain "lower level" concepts as well as all calculations. Again for brevity, I concentrate on "top" levels of explanation, with only a few incursions into deeper levels. In an actual course, the teacher/instructor will need to explain the underlying principles at any level only as they are introduced within the context of a power curve (this is where this method differs from traditional ones).

In the second part of this model, I focus on an important application of the power-speed concept (fuel management). Practical applications may help students realize the importance of understanding basic principles to optimize aircraft performance and control during actual flight.

Finally, it would be best to coordinate lectures with flight-training exercises where the same principles are illustrated during actual flight. These exercises may, for instance, consist of determining the power curve for the trainer aircraft under specific conditions of flight. In the final section of this model, I suggest two ways of empirically estimating the level-flight power curve for a propeller aircraft.

\section{What is behind the power curve?}

Let's examine Figure 2. If you can remember the shape of this curve (which by the way holds true for both mechanical and natural non-hovering flight - i.e. it applies similarly to a flying airplane or bird) you will be closer to unravelling the secrets of flight and understanding how a 


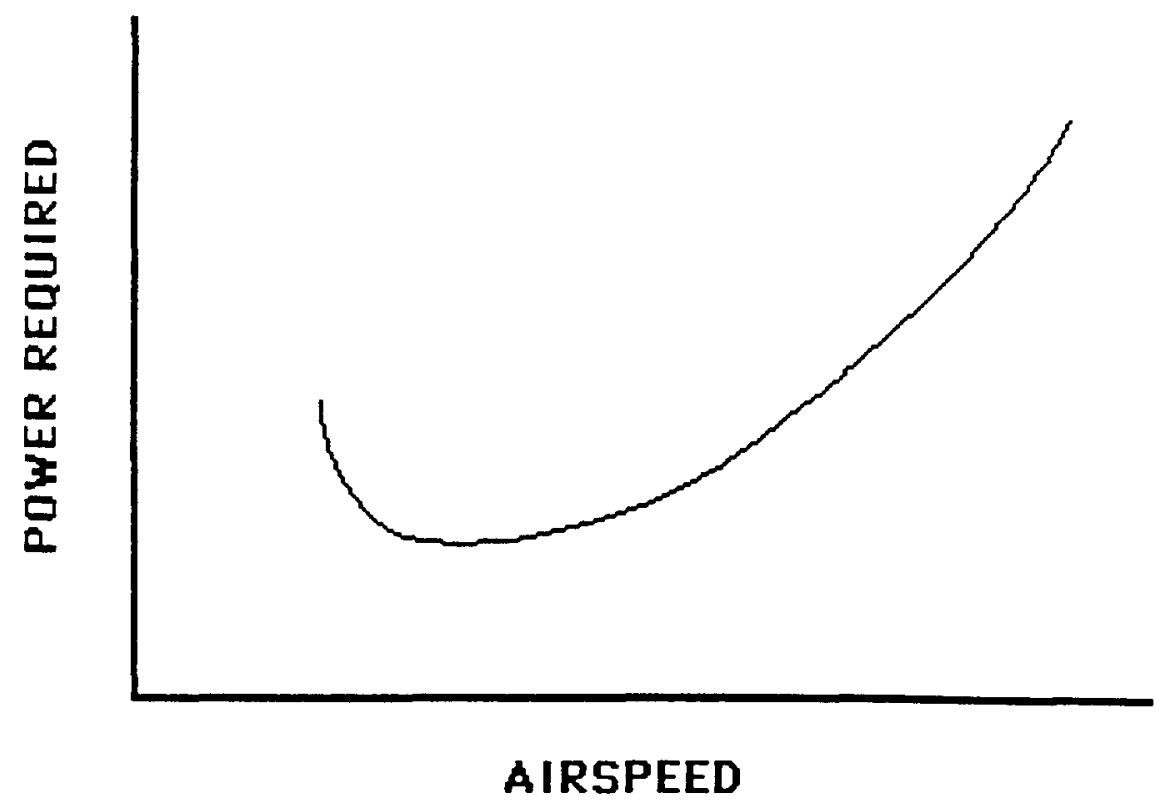

Figure 2. Power required by a propeller aircraft to maintain straight-and-level flight at different steady airspeeds.

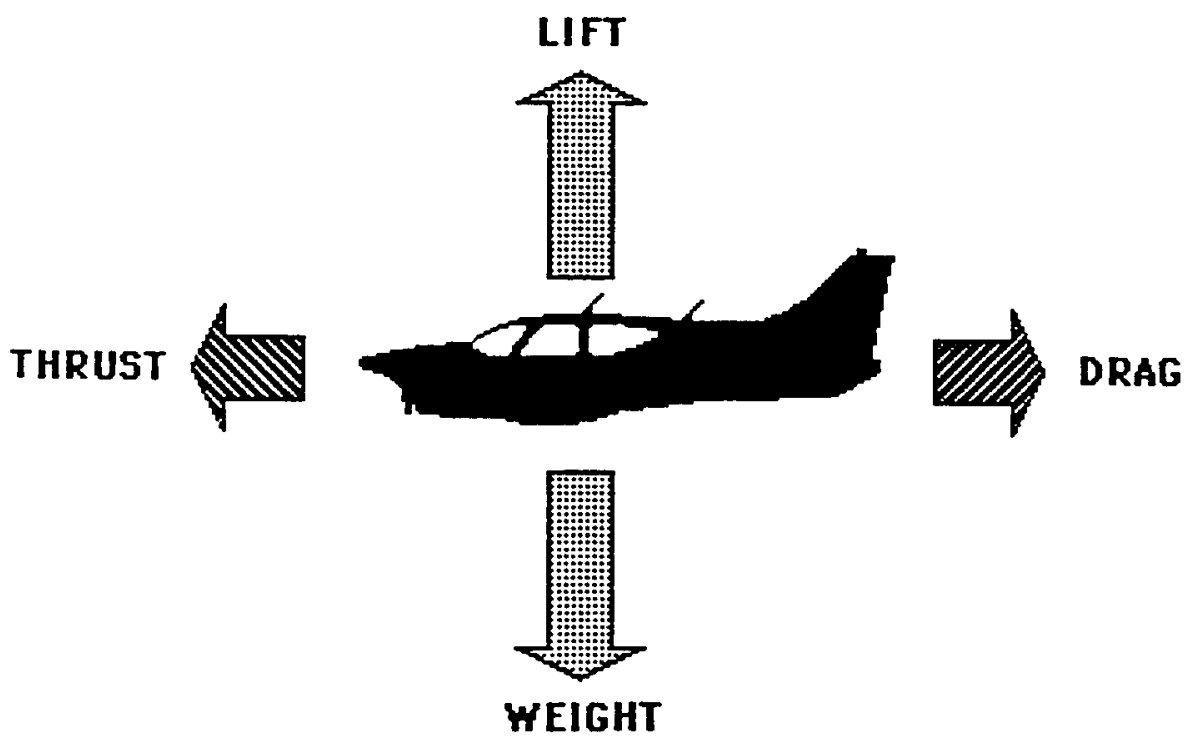

Figure 3. In straight-and-level flight at some steady speed, the four forces are in equilibrium as follows: weight is balanced by lift, and thrust is equal and opposite to drag. Notice that lift is normally much larger than thrust during level flight. 
pilot can adjust power and speed to manage the aircraft's fuel in a variety of different ways. The right-hand portion of the curve (where power required increases with airspeed) intuitively makes sense. What this part of the curve says is that if you want to fly faster, more power is required in order to maintain level flight. Since fuel consumption is a function of the amount of power used (in a propeller aircraft), the power curve also reflects fuel flow required (gal/hr) at different airspeeds. Now look at the left side of the curve. This side of the power curve (better known as the region of reversed command) indicates that if you want to slow down, more engine power will be required to maintain level flight. How can this be? Well, in order to understand this powerspeed relation we will have to dig a bit further to find out the main factors that result in this peculiar U-shaped curve.

\section{The forces required for straight-and-level flight}

The forces required for straight-and-level, unaccelerated flight are determined by the weight of the aircraft and the drag produced by it during flight. Weight, being the result of gravity, is a force that pulls the airplane downward towards the earth, while drag is a rearward, retarding force that pulls the aircraft in the opposite direction of flight. Thus, to remain aloft in forward motion, an aircraft must provide just enough upward force (lift) to support its weight , and just enough forward force (thrust) to counteract drag (Figure 3). When the forces are balanced in this way, no accelerations or deccelerations occur along any of the axes of flight and the aircraft follows a straight-and-level path as it moves forward. To determine the amount of engine power required by an aircraft flying under these conditions (and understand the power curve) we will need to know how these four aerodynamic forces interact to result in steady level flight at different speeds.

Lift is the net upward force (usually measured in lbs.) produced by the dynamic action of air over and under the wings. Since the weight (also in lbs.) of the aircraft remains the same regardless of airspeed, it follows that the amount of effective lift required for level flight also remains constant for any speed (Figure 4a). The way by which the same amount of lift is generated at different airspeeds, however, depends on several factors. These can be best illustrated by briefly referring to the basic lift equation:

$$
\begin{aligned}
& L=1 / 2 \cdot \rho \cdot S \cdot C_{L} \cdot V^{2}, \text { where: } \\
& L=\text { lift } \\
& \rho=\text { air density } \\
& S=\text { wing surface area } \\
& C_{L}=\text { coefficient of lift (dimensionless function of the angle of attack) } \\
& V=\text { airspeed }
\end{aligned}
$$

Since we are interested in producing a fixed amount of lift at a given altitude (i.e. level flight) and aircraft configuration (i.e. clean), we can consider air density $(\rho)$ and wing surface area $(S)$ as constant. Lift generated then will be directly proportional to the coefficient of lift $\left(C_{L}\right)$,which is nothing more than a number related to the angle of attack, and to the square of airspeed $\left(V^{2}\right)$. This really means that if we want to change the airspeed and maintain the same amount of lift required for level flight we have to vary the angle of attack accordingly. We can generate the same amount of lift flying at low airspeeds with large angles of attack, or at high airspeeds with low angles of attack (Figure 4b). We can summarize this relationship by stating: (1) the generation of lift (in a fixed-wing aircraft) requires some forward motion (relative to the 

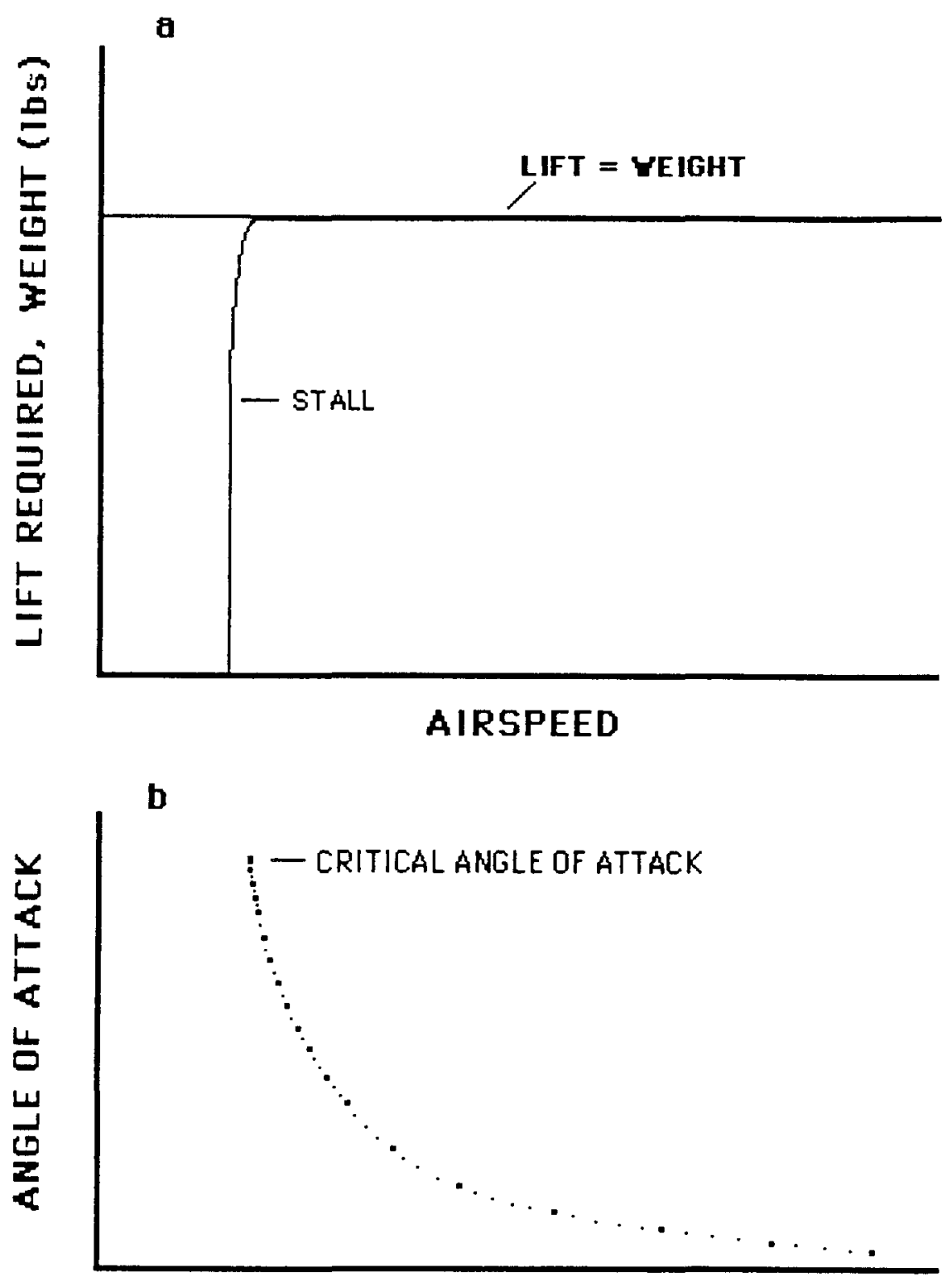

AIRSPEED

Figure 4. a) Lift required to maintain straight-and-level flight at different airspeeds. At stall speed, lift available drops precipitously. This occurs just after the critical angle of attack has been reached. b) The inverse relationship between angle of attack and airspeed during level flight. If angle of attack is increased, airspeed will decrease. Notice that only one angle of attack corresponds to any given steady speed. Because of this, angle of attack is the primary control of airspeed during steady (unaccelerated) flight. 
airmass), (2) angle of attack and airspeed vary inversely and, (3) each airspeed requires a specific angle of attack to maintain steady flight.

As it turns out, the inverse relation between angle of attack and airspeed to produce the same effective lift is at the heart of the power curve. We have already seen that, aside from lift, an aircraft must produce enough thrust to counteract drag if it is to remain flying forward, horizontally (Figure 3). There are two forms of drag: induced drag and parasite drag (Figure 5). Induced drag (exclusively associated with the production of lift) varies directly with angle of attack. This can only mean that this type of drag, like the angle of attack, varies inversely with airspeed (in fact it varies inversely with the square of speed). For example, reducing airspeed by half will increase induced drag four times. Let's stop to think about this for a moment. If an airplane is to maintain adequate lift at very low speeds it must do so by an increased angle of attack. The penalty of a higher angle of attack is, of course, greater induced drag that must be equally opposed by increasing thrust.

Now, let's not forget parasite drag (caused by the disruption of airflow around all of the plane's surfaces). This form of drag, in contrast to induced drag, increases with increasing airspeed, thus it only becomes significant at high speeds (Figure 5). Because the high airspeeds are adequate to produce sufficient lift, the aircraft can maintain level flight with a very small angle of attack (hence low induced drag). Although induced drag plays a minimal role in the high speed range, parasite drag becomes increasingly larger opposing the forward motion of the aircraft. Thus, the penalty for providing lift at very high speeds is increased parasite drag which must be balanced by increasing thrust.

In unaccelerated straight-and-level flight, the amount of thrust that the aircraft must produce is determined by the sum of induced and parasite drags (Figure 6a). Since both types of drag vary with airspeed in opposite ways (as one goes up, the other one comes down), there must be an intermediate airspeed at which the total drag, thus thrust required for level flight, is minimum. This happens to be at the point where both drag-lines cross each other, largely because they vary symmetrically (induced drag decreases as $1 / \mathrm{V}^{2}$, and parasite drag goes up with $\mathrm{V}^{2}$ ). If you remember, effective lift required to maintain level flight does not vary with airspeed. Therefore, the ratio of lift to drag is maximized $\left(\mathrm{L} / \mathrm{D}_{\max }\right)$ at this intermediate speed. At this airspeed the wings are most efficient in producing lift and, as we will see later, this has an important implication in terms of fuel economy.

To summarize, an aircraft flying horizontally at some steady speed has to provide sufficient lift and thrust to balance weight and drag respectively. Although the amount of effective lift required to maintain level flight does not vary with airspeed, the amount of thrust does. Thrust required is determined by the tradeoff between angle of attack and airspeed necessary to generate a given amount of effective lift. Now, let's see how we can relate changes in the force required to propel an aircraft forward to the amount of power required for level flight.

\section{The power required for straight-and-level flight}

The power required to propel an aircraft can be obtained by multiplying the forward force required (thrust) to move it times the airspeed at which it is being propelled. The power required (usually measured either in horsepower or foot-pounds) for flight can be expressed as follows:

Power $=$ force $\times$ velocity, or

$\operatorname{Pr}=T \cdot V$, where: 


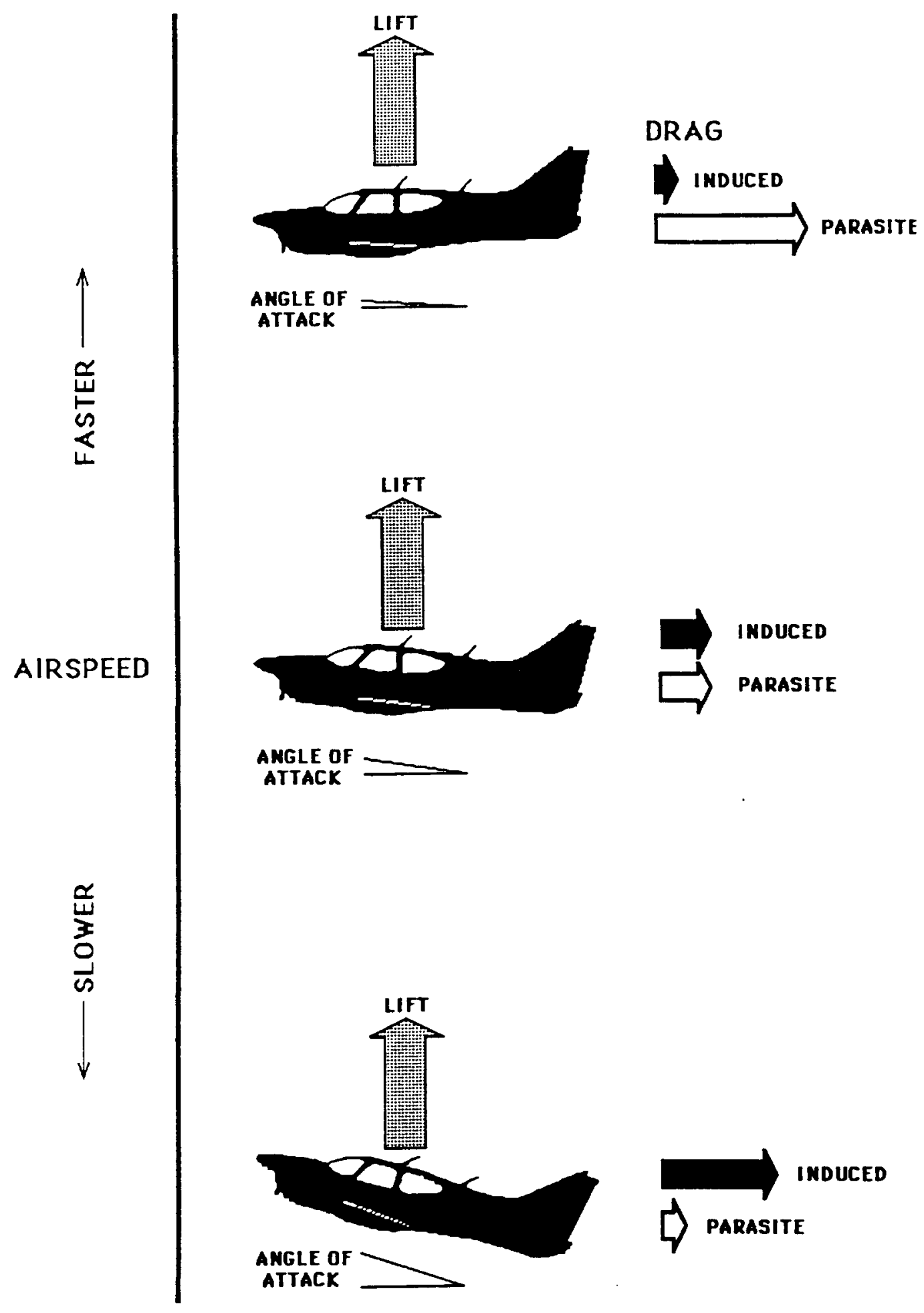

Figure 5. Induced and parasite drag as a function of airspeed during steady-level flight. Induced drag decreases with speed, while parasite drag increases. Notice that angle of attack (acute angle between the average chordline of the wing and the relative wind) decreases with airspeed, while the amount of effective lift required to maintain level flight remains constant. 


$$
\begin{aligned}
& P r=\text { Power required } \\
& T=\text { thrust } \\
& V=\text { airspeed }
\end{aligned}
$$

We could equally determine the power required to propel the airplane forward by multiplying drag (since it is equal to thrust) times airspeed. Since there are two forms of drag, we can also split total power required into two distinct components. One component would be the power required to overcome induced drag, or induced power required $\left(\mathrm{Pr}_{\mathrm{i}}\right)$, and the other the power necessary to overcome parasite drag, or parasite power required ( $\mathrm{Pr}_{\mathrm{p}}$ ). By adding these two components, the main characteristics of the power curve become apparent.

Let's take a closer look at how induced and parasite power vary with airspeed (Figure 6b). As you study figure 6 , note that the airspeed at which a aircraft has the minimum thrust required (at $\mathrm{L} / \mathrm{D}_{\max }$ ) is not the speed that results in minimum power required. Why? Well, unlike induced and parasite drag which vary inversely but symmetrically, the two components of power vary asymmetrically with airspeed. This asymmetry can be explained by taking a closer look at the formula for power required stated above:

Let's call induced drag, $D_{i}$, then:

$D_{i} \propto 1 / N^{2}$ (The symbol $\propto$ simply means that $D_{i}$ is proportional to the inverse of the square of airspeed)

Since $\operatorname{Pr}=\mathrm{D} . \mathrm{V}$, then we can express the induced power required as:

$$
\begin{aligned}
& \operatorname{Pr}_{\mathrm{i}}=\mathrm{D}_{\mathrm{i}} \cdot \mathrm{V} \text {, or, substituing }\left(=\mathrm{D}_{\mathrm{i}}\right) \text { for }\left(\propto 1 / \mathrm{V}^{2}\right): \\
& \operatorname{Pr}_{\mathrm{i}} \propto\left(1 / \mathrm{V}^{2} \cdot \mathrm{V}\right)==================\operatorname{Pr}_{\mathbf{i}} \propto 1 / \mathrm{V}
\end{aligned}
$$

Similarly, if we call parasite drag, $D_{p}$, then:

$D_{p} \propto V^{2} \quad\left(D_{p}\right.$ is proportional to the square of airspeed)

Since $\operatorname{Pr}=\mathrm{D} . \mathrm{V}$, then we can express the parasite power required as:

$$
\begin{aligned}
& \operatorname{Pr}_{p}=D_{p} \cdot V, \text { or, substituing }\left(=D_{p}\right) \text { for }\left(\propto V^{2}\right): \\
& \operatorname{Pr}_{p} \propto\left(V^{2} \cdot V\right)=====================>\operatorname{Pr}_{p} \propto V^{3}
\end{aligned}
$$

We can see that while induced power decreases rather slowly with increasing airspeed (i.e. it varies with the inverse of airspeed), parasite power increases very rapidly with airspeed (i.e. it varies with the cube of airspeed). For example, doubling airspeed will cut in half the power required to overcome induced drag, but will increase the power required to overcome parasite drag by eight times! As with the drag-thrust curve we can add the induced and parasite components of power to obtain the total power required (Figure 6b). The bottom of this curve is rather skewed to the left (for the reasons given above) and consequentely the airspeed for minimum power required $\left(\mathrm{P}_{\min }\right)$ is not the airspeed where the induced and parasite curves cross. In fact, at minimum power, the induced power is three times the parasite power. As a result of this, the airspeed for minimum power is slower than that for minimum thrust (or $L / \mathrm{D}_{\max }$ ). 

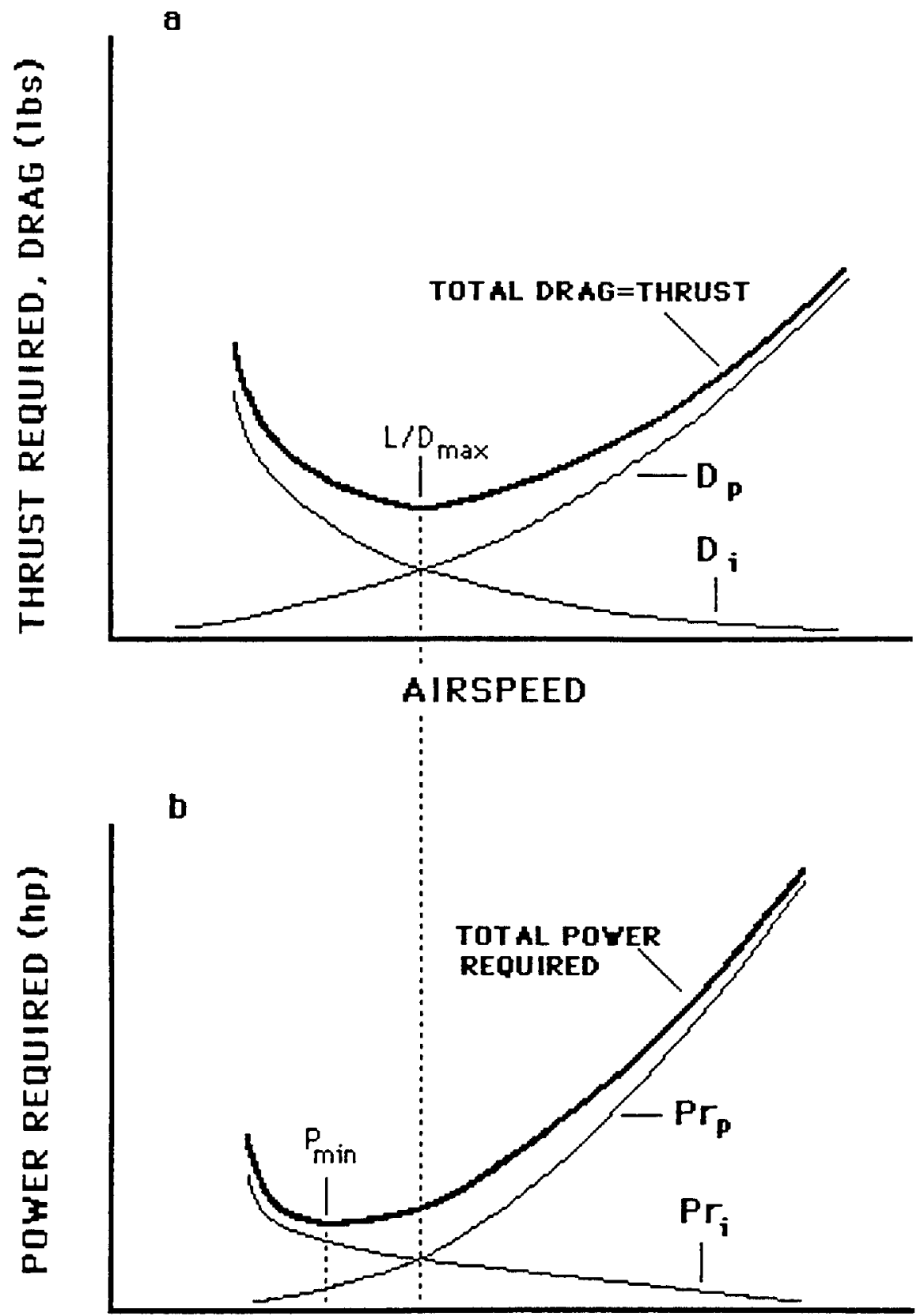

AIRSPEED

Figure 6. a) Total drag and thrust required for level flight are determined by adding the two components of drag: induced $\left(D_{i}\right)$ and parasite $\left(D_{p}\right)$ drag. b) Total power required for level flight and its two components: induced $\left(\operatorname{Pr}_{i}\right)$ and parasite $\left(\operatorname{Pr}_{\mathrm{p}}\right)$ power. Notice that the speed for minimum power required (Pmin) is not the same as that for minimum thrust required (at $\left.\mathrm{L} / \mathrm{D}_{\max }\right)$. Also, note that at any given steady airspeed, if power applied exceeds power required, the aircraft will climb (it will convert the excess kinetic energy into potential energy). On the other hand, if power applied is less than the power required to maintain a given speed, the aircraft will descend (it will transfer its potential energy into kinetic energy). In both cases, kinetic energy (and the resulting airspeed) will remain constant. The rate of climb or descent, however, will depend on the difference between power applied and required. Because of this, power is the primary control of rate of climb or descent during steady (unaccelerated) flight. 
At this point, I would like to make an important distinction between power required as we have derived it, and engine power. The former represents the aerodynamic power required to propel the aircraft, and thus it is called thrust-power. Engine power, on the other hand, is the power output measured either at the crankshaft (in which case it is called brake power) or at the propeller shaft (in which case it is called shaft power). Engine power required to maintain level flight is always greater than thrust-power because the propeller is not $100 \%$ efficient (some energy is lost in the process of transfering engine into useful propulsive power). Knowing the propeller efficiency would allow us to estimate shaft power required for level flight. Shaft power is thrustpower divided by propeller efficiency.

Before explaining one of the applications of this power-speed relationship, I want to point out what limits both ends of the level-flight speed range. Take a look at figure $6 \mathrm{~b}$. At the low (left) end of the power curve, one cannot keep increasing the angle of attack forever. Once a critical angle of attack is reached (and the maximum coefficient of lift, or $C_{\mathrm{Lmax}}$, is achieved), the wings suddenly lose all lift, and the plane stalls (Figure 4). The message? You cannot fly any slower than stall speed. At the high (right) side of the curve you can increase power only by so much to oppose the increasing parasite drag. At this end, the fastest level-flight speed is limited by power available.

\section{Significance of the power curve to fuel management}

Aircraft engines, such as a reciprocating-piston engine, convert chemical energy from fuel into usable power. This stored energy is converted to power by the oxygen-requiring combustion of fuel inside the engine. The power generated by this controlled "burning" of fuel is then used to move a propeller which in turn provides the necessary thrust force to overcome drag and propel the aircraft forward. The rate at which fuel is burnt (in gal/hr) by the piston engine is therefore a function of the amount of power being used.

Not surprisingly, the power curve is the key concept to understand the energy requirements for flight. For simplicity, let's assume we want to "manage" a fixed amount of fuel for a given flight (e.g. no refueling allowed). Usually, when managing a given amount of fuel what we are really trying to do is to maximize or minimize some variable (e.g. time or distance). Once we have decided what is it we want to maximize or minimize, the power curve will give us the answer. It will tell us where in the airspeed range for level flight we should operate to achieve our goal. Let's look at some examples from least to most significant ones (see Figure 7).

\section{Minimum controllable airspeed}

How about flying at the slowest possible airspeed? We have already seen this speed when we talked about stall speed ( 1 in Figure 7 ). The important message here is that flying at the slowest possible speed to maintain level flight will result in more power and fuel consumed per hour or distance than at some faster speeds.

\section{Maximum cruise airspeed}

Perhaps, you may want to fly at the fastest speed possible to minimize time between two points? As we stated previously, maximum cruise speed is limited by power available (4 in Figure 7). Again, not a wise decision if you care about fuel economy. 


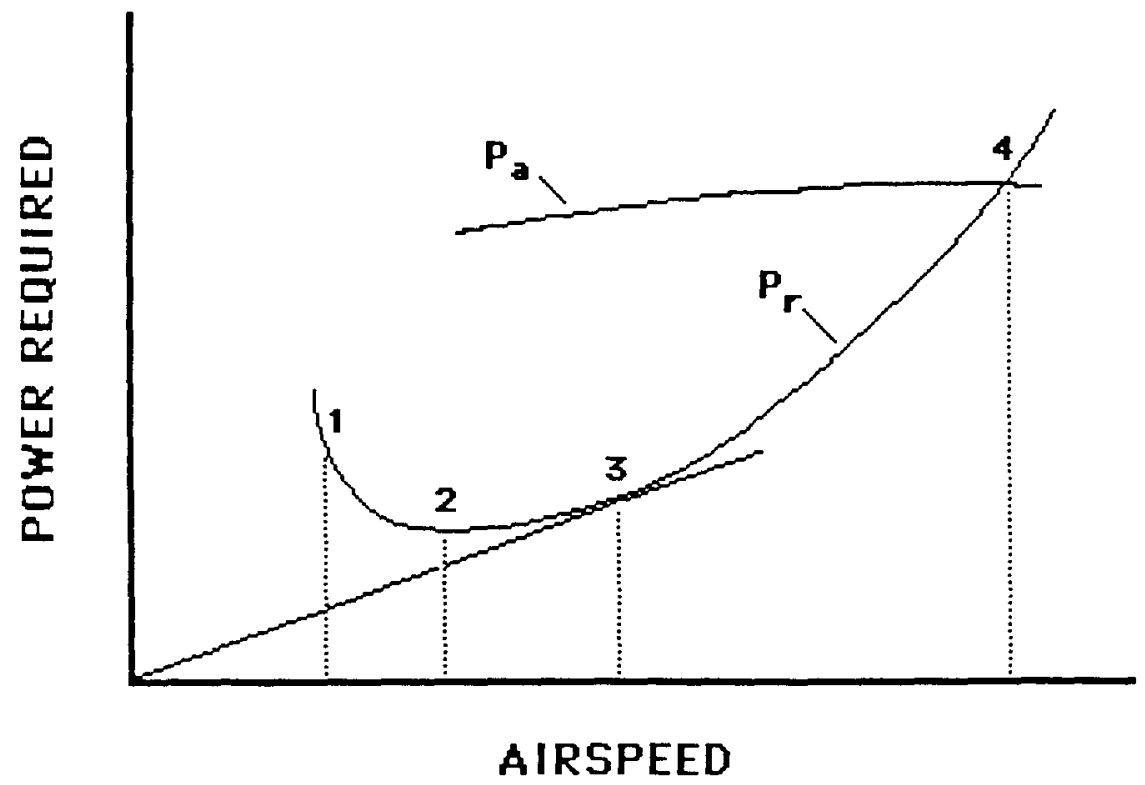

Figure 7. Power required $\left(\mathrm{P}_{\mathrm{r}}\right)$, thrust-power available $\left(\mathrm{P}_{\mathrm{a}}\right)$, and some important level-flight airspeeds: (1) minimum controllable, (2) maximum endurance, (3) maximum range, and (4) maximum cruise. Note that the slowest level speed is not limited by power available. At maximum cruise speed, however, the pilot is applying all of the available power (wide open throttle) in order to maintain level flight. 


\section{Maximum endurance airspeed}

How about maximizing time that you can remain aloft? The airspeed for this should be located at the point of lowest power required (because that is where fuel consumption rate is at its lowest). It makes sense, this is where you get most hours out of your fixed amount of fuel. This airspeed ( 2 in Fig. 7) known as the maximum endurance speed is very important if you get into airtraffic/landing delays and are low on fuel.

\section{Maximum range airspeed}

Now, for the most important airspeed in terms of getting the most miles per gallon of fuel. What is the speed that will maximize the distance that you can fly on a given amount of fuel? What we are trying to do here is to maximize the ratio of distance to total fuel. Since we can divide both terms of this ratio by time, we are also trying to maximize the ratio of airspeed to fuel rate (which is proportional to power used). This speed, know as maximum range airspeed, is found by drawing a tangent line from the origin to the power curve. The point where the tangent line touches the power curve is where the ratio of airspeed to power required is maximized ( 3 in Fig. 7). As we know, at this speed total drag is minimized, and thus the ratio of lift to drag is maximum ( $\left(\mathrm{L}_{\max }\right)$. In other words, this is where it is cheapest for the aircraft to support and carry its own weight from one location to another.

\section{Measuring the power curve for level flight}

Student pilots could benefit tremendously from simply attempting to determine the power curve for their trainer aircraft. First, they can further their understanding of flight dynamics by systematically experimenting with aircraft control (pitch and throttle) in order to achieve a given state of aircraft performance (e.g. level flight at different steady airspeeds). This should be particularly useful, for example, for getting a "feel" of how the different aerodynamic forces interact at different airspeeds to result in steady flight. Second, the exercise can give them the opportunity to empirically test the effects of numerous factors (weight, altitude, configuration) on aircraft performance. Finally, by plotting the power curve for their aircraft, and obtaining some "important airspeeds" under specific flight conditions, they can appreciate the usefulness of having such knowledge in terms of flight planning and management.

Here, I suggest two methods for estimating the power curve for a propeller aircraft. The first one indirectly measures engine power, while the second method measures thrust-power. Neither method is perfect. Both lead to some errors which are noticeable at certain speeds. A comparison of the results using both methods would be useful in discussing these errors. Students can also compare maximum endurance and maximum range airspeeds which they have calculated with values given in the Pilot's Operating Handbook for the trainer aircraft, or with the following approximations for single-engine, fixed-gear aircraft (Kershner, 1985):

$$
\begin{aligned}
& \text { Maximum endurance }=1.2 \times \text { power-off, clean stall speed (CAS) } \\
& \text { Maximum range }=1.5 \times \text { power-off, clean stall speed (CAS) }
\end{aligned}
$$

When plotting the power curve it will be important to correct for airspeed errors by converting indicated (IAS) to calibrated speeds (CAS), and better still to standarize them to true airspeeds (TAS) if density altitude during flight is known. 


\section{Method 1: Engine RPM}

This method relies on the fact that in fixed-pitched propeller aircraft, propeller and engine speed (RPM) are the same and can be read directly from the tachometer. One can also use this method for constant-speed propeller aircraft. But in this case, instead of using RPM, one would use manifold pressure. Both engine speed and manifold pressure give an indirect measurement of engine power output.

The idea here is to establish different steady airspeeds by varying pitch attitude (hence angle of attack), and then adjusting power as necessary to maintain level flight. Thus, it may be helpful to select a range of airspeeds (e.g. from just above stall to maximum cruise) prior to the flight. During flight, once a selected speed is established, simply record the corresponding engine RPM from the tachometer.

\section{Method 2: Power-off glide}

It may seem strange to measure power required to maintain level flight by performing power-off glides. However, this method is based on the fact, that if not enough power (thus thrust) is provided to overcome drag and maintain level flight, the aircraft will simply descend at a given sink rate. Why? Once the aircraft is trimmed to fly at a given airspeed it will continue to maintain that forward speed even if it means losing potential energy (altitude). If we supply no power at all, then all of the forward force needed to overcome drag will have to come from the force of gravity (which is nothing more than the weight of the aircraft). Under these conditions, the aircraft will simply lose potential energy at a rate equal to its weight multiplied by the sink speed. This "force-times-speed" is nothing else than the power that would be required to maintain level flight (to arrive at this, use a simple analysis of the velocity and force vectors involved in gliding flight). Thus, we can express power required for level flight as follows:

$$
\begin{aligned}
& P_{r}=W \cdot V_{Z}, \text { where: } \\
& P_{r}=\text { thrust-power required to maintain level flight } \\
& W=\text { weight of aircraft } \\
& V_{Z}=\text { sink speed }
\end{aligned}
$$

Sink speed is a function of forward speed. All we need for estimating the level-flight power curve is the aircraft's forward speed, its sink speed, and its weight. Note that if you plot sink speed ( $y$ axis) versus forward speed ( $\mathrm{x}$ axis) you will get a curve (called glide polar) that looks very much like a power curve. The similarity is not coincidental, and glide performance speeds (minimum sink, and maximum glide) have their equivalents in the power curve (maximum endurance, and maximum range respectively).

The idea here is to set up a number of power-off glides at different steady airspeeds and measure the time it takes to descend a given vertical distance (e.g. $300 \mathrm{ft}$ ). The altitude loss (read from the altimeter) divided by the time (with a stopwatch) will give you the sink speed. The weight of the aircraft can be later estimated by substracting fuel burnt up to the time of the exercise from takeoff weight. 


\section{Conclusions}

The purpose of this paper was to outline a new way of teaching principles of flight to student pilots. By removing some of the initial learning obstacles encountered by beginner students, this "pilot" oriented approach may help to improve the understanding of flight theory reached by civilian pilots and in so doing, promote proficiency and safety in the skies. The educational strategy proposed here may also provide a model for standarizing ground school curricula, and for integrating theory and practice during flight training. At a time when most of the qualified professional pilots in the commercial fleet are going to be supplied by civilian training programs, a close scrutiny of all aspects of civilian pilot education in the 1990s' is timely. 


\section{References}

Dole, C.E. (1989). Flight Theory for Pilots. Casper: I.A.P., Inc.

F.A.A. (1980a). Flight Training Handbook. AC 61-21A. Federal Aviation Administration, U.S. Department of Transportation (see p. 269).

F.A.A. (1980b). The Pilot's Handbook of Aeronautical Knowledge. AC 61-23B. Federal Aviation Administration, U.S. Department of Transportation (see p. 9).

F.A.A. (1987). The power curve. Accident Prevention Program. Reprinted in: M. Navarre and N.W. Miller (eds.), Airguide Manual: Flight Operations Handbook. Long Beach: Airguide Pub.

Hurt, H.H., Jr. (1965). Aerodynamics for Naval Aviators. NAVWEPS 00-80T-80, Government Printing Office.

Jeppesen-Sanderson (1988). Private Pilot Manual. Englewood: Jeppesen Sanderson, Inc.

Jeppesen-Sanderson (1989). Aviation Fundamentals. Englewood: Jeppesen Sanderson, Inc.

Kershner, W.K. (1979). The Student Pilot's Flight Manual. Ames: Iowa State Univ. Press.

Kershner, W.K. (1985). The Advanced Pilot's Flight Manual. Ames: Iowa State Univ. Press.

McCormick, B.W. (1979). Aerodynamics, Aeronautics, and Flight Mechanics. New York: Wiley \& Sons.

Miller, N.W. (1987). Ed:sor's note to the "region of reverse command": the backside of the power curve. In: M. Navarre and N.W. Miller (eds.), Airguide Manual: Flight Operations Handbook. Long Beach: Airguide Pub.

Milne-Thomson, L.M. (1958). Theoretical Aerodynamics. New York: Macmillan (Dover edition, 1973).

Mises, R. von (1945). Theory of Flight. New York: McGraw-Hill Book Co. (Dover edition, 1959).

Navarre, M. (1987a). Drag. In: M. Navarre and N.W. Miller (eds.), Airguide Manual; Flight Qperations Handbook. Long Beach: Airguide Pub.

Navarre, M. (1987b). Backside of the power curve. In: M. Navarre and N.W. Miller (eds.), Airguide Manual: Flight Operations Handbook. Long Beach: Airguide Pub.

Prandtl, L. and Tietjens, O.G. (1934). Applied Hydro- and Aero-mechanics. United Engineering Trustees (Dover edition, 1957).

Schmidt-Nielsen, K. (1972). Locomotion: energy cost of swimming, flying, and running. Science 177: 222-228. 
Taylor, C.R., N.C. Heglund, and G.M.O. Maloiy (1982). Energetics and mechanics of terrestrial locomotion. J. Exp. Biol. 97: 1-21.

Tucker, V.A. (1973). Bird metabolism during flight: evaluation of a theory. J. Exp. Biol. 58: 689-709.

Warner, E.P. (1936). Airplane Design: Performance. New York: McGraw-Hill Book Co. 